\title{
Pengaruh Daya Tarik Iklan Swipe Up Online Shop di Instagram terhadap Minat Beli Pengguna Instagram
}

\author{
Yusro Khoyriah, Eko Harry Susanto \\ yusrokhoyriah73@gmail.com,ekos@fikom.untar.ac.id \\ Fakultas Ilmu Komunikasi Universitas Tarumanagara
}

\begin{abstract}
In this study, there are 2 variables, namely $X$ (Attractiveness) $Y$ (Purchase Interest). Researchers took this research sample based on purposive sampling, namely 154 respondents. This study uses 2 times the distribution of the questionnaire which is useful to prove whether it is valid or not. Data analysis used by the author is the IBM SPSS STATISTICS 22 program, this program is used and helps the author as an alternative to find out whether there is really an effect between Variable $X$ and Variable $Y$ and whether the coefficient results obtained are positive or negative. With these results, the Attractiveness of Ads greatly influences Purchase Intention because indeed all results are declared Valid and Reliable.
\end{abstract}

Keywords: advertising, attraction, purchase interest, social media

\begin{abstract}
Abstrak
Dalam penelitian ini terdapat 2 Variabel yaitu X (Daya Tarik) Y (Minat Beli), Peneliti mengambil sampel penelitian ini Berdasarkan Purposive Sampling yaitu 154 Responden. Penelitian ini menggunakan 2 kali pembagian kuesioner yang berguna untuk membuktikan sudah Valid atau belum. Analisis Data yang digunakan penulis yaitu program IBM SPSS STATISTICS 22, program ini digunakan dan membantu penulis sebagai alternative untuk mengetahui apakah benar ada pengaruh antara Variabel X (Daya Tarik Iklan Swipe up di Instagram) dan Variabel Y ( Minat Beli pengguna instagram) dan apakah hasil koefisien yang didapat adalah positif atau negatif . Dengan hasil tersebut, daya tarik iklan sangat berpengaruh terhadap minat beli karena memang semua hasil dinyatakan valid dan reliabel.
\end{abstract}

Kata Kunci: daya tarik, iklan, media sosial, minat beli

\section{Pendahuluan}

Iklan juga diartikan sebagai bentuk komunikasi nonpersonal yang menjual pesan-pesan persuasif dari sponsor yang jelas untuk mempengaruhi orang membeli produk dengan membayar sejumlah biaya untuk media. Seiring berjalan waktu Online shop yang mengupload barang-barangnya di Media Sosial membutuhkan Iklan agar Online shop yang mereka jalankan dapat tersebar sangat cepat. Instagram memang memiliki banyak fitur di dalamnya tetapi untuk Online shop di luar sana yang ingin cepat tersebar luas mereka banyak menggunakan fitur Instagram Stories swipe up. Fitur ini digunakan dengan cara menyisipkan Link atau Tautan URL di Instagram Stories, dengan cara itulah Online shop dapat langsung dilihat oleh masyarakat luas tanpa harus datang ke halaman Instagram Online shop tersebut, ketika iklan tersebut muncul dapat langsung dilihat dan swipe up lalu akan langsung masuk ke halaman profil Instagram yang dituju. 
Langkah atau cara swipe up di Instagram Stories dapat dikatakan sangat mudah, Hanya saja, ada syarat khusus untuk dapat menggunakannya seperti pengguna Instagram harus memakai akun bisnis dan memiliki minimal 10.000 followers atau pengguna akun Instagram yang sudah harus terverifikasi (centang biru). Berbagai cara dilakukan online shop agar dapat memengaruhi Pengguna Instagram untuk membeli produknya karena iklan swipe up di Instagram bukan hanya dalam bentuk foto saja tetapi dengan video juga agar menambah minat beli orang-orang yang melihat iklan tersebut. Minat beli mucul setelah adanya proses evaluasi alternatif, di dalam proses evaluasi seseorang akan membuat suatu rangkaian pilihan mengenai produk yang hendak dibeli atas dasar merek maupun minat.

\section{Daya Tarik Iklan Swipe Up Online Shop pada Instagram}

Daya Tarik Iklan itu ada 3 yang pertama harus bermakna menunjukan manfaat, iklan harus percaya bahwa memberikan informasi dan iklan harus memiliki ciri khas dan berbeda sehingga membuat produk beda dari yang lain. Daya Tarik yang didapat dari iklan swipe up online shop di Instagram sangatlah beragam, satu online shop dengan online shop yang lainnya berlomba-lomba membuat dan memasang iklan yang kreatif.

\section{Minat Beli Pengguna Instagram}

Minat Beli menjelaskan bahwa pengaruh eksternal, kesadaran akan kebutuhan, pengenalan produk dan evaluasi alternatif adalah hal yang dapat menimbulkan minat beli konsumen. Pengaruh eksternal ini terdiri dari usaha pemasaran dan faktor sosial budaya. Menurut Schiffman dan Kanuk (2004). Pengaruh eksternal itu sangatlah kuat karena ada usaha pemasaran berupa memasang iklan swipe up barang yang mereka jual dan Faktor sosial budaya juga.

\section{Metode Penelitian}

Pendekatan yang peneliti gunakan kali ini adalah kuantitatif. Penelitian Kuantitatif adalah suatu pendekatan penelitian yang secara primer menggunakan paradigma Post Positivisme dalam pengembangan Ilmu Pengetahuan seperti pemikiran tentang sebab akibat, reduksi kepada variabel, hipotesis dan pertanyaan spesifik, menggunakan pengukuran dan observasi serta pengujian teori) menggunakan strategi penelitian seperti eksperimen dan survey yang memerlukan data statistik. Metode Penelitian adalah cara ilmiah untuk mendapatkan data dengan tujuan dan kegunaan tertentu.

Metode Penelitian juga dapat disebut suatu teknik atau cara untuk mencari, memperoleh, menyimpulkan atau mencatatat data primer maupun sekunder yang digunakan untuk keperluan menyusun suatu karya ilmiah dan kemudian menganalisa faktor-faktor yang berhubungan dengan pokok-pokok permasalahan sehingga akan terdapat suatu kebenaran data-data yang diperoleh. Dalam penelitian ini penulis menggunakan metode penelitian survey. Menurut data yang dirilis Napoleon Cat, pada periode Januari-Mei 2020, pengguna Instagram di Indonesia mencapai 69,2 Juta ( 69.270.000) orang. Pencapaian itu merupakan peningkatan dari bulan ke bulan atas penggunaan platform berbagi foto ini atau Instagram.

Teknik pengambilan sampel dalam penelitian ini adalah dengan menggunakan non-probability sampling, yaitu teknik pengambilan sampel yang tidak memberi peluang atau kesempatan yang ama bagi unsur atau anggota populasi yang dipilih 
untuk menjadi sampel. Jenis non probabilty sampling yang digunakan adalah jenis purposive sampling yaitu Penulis menggunakan pertimbangan sendiri dengan cara sengaja untuk memilih anggota sampel yang dianggap dapat memberikan informasi yang diperlukan oleh penulis. Oleh karna itu Penulis menggunakan Purposive Sampling untuk menentukan sampel yaitu memerlukan anggota sampel sebanyak 154 orang. Penulis menentukan 154 orang karena menggunakan purposive sampling mempertimbangkan sendiri secara sengaja anggota sampel yang dianggap cukup. Kuesioner yang disebarkan pada percobaan pertama maupun kedua itu menggunakan skala Likert.

\section{Hasil Temuan dan Diskusi}

Berdasarkan penelitian yang dilakukan, penulis mendapatkan pada percobaan pertama yaitu 20 Responden tetapi hasil Uji Validitas menunjukkan bahwa tidak valid lalu dilanjutkan pada percobaan kedua penulis membagikan Kuesioner kepada 154 Responden. Jumlah Responden yang aktif instagram yaitu 98.1\%. Lalu Percobaan kuesioner pertama di bagikan kepada 20 orang pertama untuk di uji validitas pearson $\mathrm{X}$ (Daya Tarik) dan Y (minat beli). Lalu dipercobaan kedua kembali dibagikan Kuesioner kepada 154 Orang tetapi tanpa pernyataan yang sudah terbukti tidak valid di Variabel Minat Beli. Pada percobaan kedua ini Cara mencari nilai $r$ tabel dengan df $=(\mathrm{N}-2)$ yaitu (154-2) pada signifikansi 5\% pada distribusi nilai $\mathrm{r}$ tabel statistic.

Maka, diperoleh nilai $r$ tabel sebesar 0,158. Dalam Hasil Uji Validitas ketika kuesioner dibagikan kepada 20 orang pertama Variabel X dinyatakan valid tetapi pada Variabel Y hasilnya ada yang Tidak Valid. Maka, penulis memutuskan bahwa kuesioner ada yang harus melalui revisi lagi lalu kembali dibagikan kepada responden yang lebih banyak yaitu 154 Responden. Ketika penulis sudah membagikan ulang kuesioner kepada 154 Responden hasilnya variabel X dan Y dinyatakan valid dari 15 Pernyataan. Ada juga uji eliabilitas kuesioner dibagikan kepada responden yaitu melalui dua kali percobaan. Perobaan pertama dibagikan kepada 20 orang responden dan ketika diuji kuesioner tersebut variabel minat beli (Y) ada yang tidak reliabel.

Lalu Penulis membagikan pernyataan untuk yang kedua kalinya dengan mengubah Pernyataan yang ada di variabel minat beli (Y) tersebut dengan membenarkan dan membagikan ulang kuesioner kepada 154 Orang dan pada saat diuji ulang Cronbarch Alpha harus lebih dari 0,06, lalu hasil dari pembagian kuesioner kedua kalinya yaitu Cornbarch Alpha Pada variabel X yaitu 0,782 , dinyatakan reliabel karena 0,782 Lebih besar (>) 0,06. Sedangkan Cornbarch Alpha Pada Variabel Y yaitu 0,779 yaitu dinyatakan Reliabel karena 0,779 Lebih besar (>) 0,06. Yang terakhir yaitu uji regresi linear Sederhana besarnya nilai korelasi/ hubungan (R) yaitu sebesar 0,838. Dari output tersebut diperoleh koefisien determinasi (R Square) sebesar 0,703, yang mengandung pengertian bahwa pengaruh variabel bebas (daya tarik) terhadap variabel terikat (Minat Beli) adalah sebesar 70,3\%.

Tabel 1. Hasil Uji Validitas Variabel Pearson X (Daya Tarik)

\begin{tabular}{|c|c|c|c|c|}
\hline $\begin{array}{l}\text { No. } \\
\text { Item }\end{array}$ & Thitung & $\begin{array}{c}\text { } \text { Ttabel } 5 \% \mathrm{df}=(\mathrm{N}- \\
\text { 2) }(154-2)\end{array}$ & Sig. & Kriteria \\
\hline 1 & 0,799 & 0,158 & 0,000 & Valid \\
\hline 2 & 0,744 & 0,158 & 0,000 & Valid \\
\hline 3 & 0,682 & 0,158 & 0,000 & Valid \\
\hline
\end{tabular}




\begin{tabular}{|l|l|l|l|l|}
\hline $\mathbf{4}$ & 0,826 & 0,158 & 0,000 & Valid \\
\hline $\mathbf{5}$ & 0,594 & 0,158 & 0,000 & Valid \\
\hline $\mathbf{6}$ & 0,781 & 0,158 & 0,000 & Valid \\
\hline $\mathbf{7}$ & 0,722 & 0,158 & 0,000 & Valid \\
\hline
\end{tabular}

Sumber: Olahan Data Peneliti

Tabel 2. Hasil Uji Validitas Variabel Pearson Y (Minat Beli)

\begin{tabular}{|c|c|c|c|c|}
\hline $\begin{array}{c}\text { No. } \\
\text { Item }\end{array}$ & Thitung & $\begin{array}{c}\text { Ttabel 5\% df }=\mathbf{( N -} \\
\mathbf{2})\end{array}$ & Sig. & Kriteria \\
\hline $\mathbf{1}$ & 0,721 & 0,158 & 0,000 & Valid \\
\hline $\mathbf{2}$ & 0,813 & 0,158 & 0,000 & Valid \\
\hline $\mathbf{3}$ & 0,849 & 0,158 & 0,000 & Valid \\
\hline $\mathbf{4}$ & 0,809 & 0,158 & 0,010 & Valid \\
\hline $\mathbf{5}$ & 0,708 & 0,158 & 0,000 & Valid \\
\hline $\mathbf{6}$ & 0,455 & 0,158 & 0,000 & Valid \\
\hline $\mathbf{7}$ & 0,786 & 0,158 & 0,000 & Valid \\
\hline $\mathbf{8}$ & 0,799 & 0,158 & 0,000 & Valid \\
\hline $\mathbf{9}$ & 0,832 & 0,158 & 0,000 & Valid \\
\hline
\end{tabular}

Sumber: Olahan Data Peneliti

Tabel 3. Hasil Uji Reliabilitas Cronbach Alpha X (Daya Tarik)

\section{Reliability Statistics}

\begin{tabular}{|r|r|}
\hline $\begin{array}{c}\text { Cronbach's } \\
\text { Alpha }\end{array}$ & N of Items \\
\hline .782 & 8 \\
\hline
\end{tabular}

Sumber: Olahan Data Peneliti

Tabel 4. Hasil Uji Reliabilitas Cronbach Alpha Y (Minat Beli)

\section{Reliability Statistics}

\begin{tabular}{|r|r|}
\hline $\begin{array}{c}\text { Cronbach's } \\
\text { Alpha }\end{array}$ & N of Items \\
\hline .779 & 10 \\
\hline
\end{tabular}

Sumber: Olahan Data Peneliti

Tabel 5. Hasil Uji Regresi Linear Sederhana (Daya Tarik dan Minat Beli)

Model Summary

\begin{tabular}{|l|r|r|r|r|}
\hline Model & \multicolumn{1}{|c|}{$\mathrm{R}$} & R Square & $\begin{array}{c}\text { Adjusted R } \\
\text { Square }\end{array}$ & $\begin{array}{r}\text { Std. Error of } \\
\text { the Estimate }\end{array}$ \\
\hline 1 & $.838^{\mathrm{a}}$ & .703 & .701 & 4.11635 \\
\hline
\end{tabular}

a. Predictors: (Constant), Daya Tarik

Sumber: Olahan Data Peneliti 
Yusro Khoyriah, Eko Harry Susanto: Pengaruh Daya Tarik Iklan Swipe Up Online Shop di Instagram terhadap Minat Beli Pengguna Instagram

\section{Simpulan}

Penulis telah mendapatkan hasil penelitian yang sudah diteliti lalu menyimpulkan hasil Penelitian sebagai berikut:

1. Hasil kuesioner yang dibagikan secara bertahap yaitu dua (2) kali. Tahap pertama di bagikan kepada 20 Responden dan hasil nya "tidak valid" lalu pada tahap kedua dibagikan kepada 154 Responden lalu hasilnya "valid". Untuk mendapatkan hasil tersebut penulis menggunakan uji validitas dan uji reliabilitas pada setiap butir pernyataan yang dibagikan.

2. Hasil uji regresi linear sederhana yaitu dapat disimpulkan bahwa variabel daya tarik $(\mathrm{X})$ berpengaruh terhadap variabel minat beli $(\mathrm{Y})$. Koefisien regresi bernilai positif, sehingga dapat dikatakan bahwa arah pengaruh variabel minat beli (X) terhadap minat beli (Y) adalah positif.

3. Analisis data statistik, indikator-indikator pada penelitian ini bersifat Valid dan variabelnya bersifat reliabel. Hasil tersebut didapatkan pada uji validitas, reliabilitas, dan regresi linear sederhana

4. Maka hipotesis Penelitian yang penulis dapatkan dari penelitian ini adalah ada pengaruh daya tarik iklan swipe up online shop di Instagram terhadap minat beli pengguna Instagram

5. Jika hasil penelitian dikaitkan dengan Rumusan Masalah pada Bab I yaitu, apa hal yang sangat mempengaruhi daya tarik iklan Swipe up Online shop di Instagram terhadap Minat Beli pengguna instagram. Hal yang sangat memengaruhi itu adalah sesuai dengan Indikator-indikator dan teori yang sudah penulis angkat, seperti, promosi, tujuan promosi, bauran promosi, daya tarik promosi, barang atau jasa, menarik, bermakna, bermanfaat, memberi informasi, ciri khas, dapat dipercaya, membeli produk, kebutuhan, pengenalan produk, faktor sosial budaya, sikap mengonsumsi dan minat membeli.

\section{Ucapan Terima Kasih}

Ucapan terima kasih kepada semua pihak yang turut membantu, memberi semangat dan dukungan dalam pengerjaan skripsi ini sampai selesai membuat penelitian ini.

\section{Daftar Pustaka}

Schiffman \& Kanuk. (2004). Perilaku Konsumen (edisi 7). Jakarta: Prentice Hall. Sugiyono. (2012). Metode Penelitian Kuantitatif, Kualitatif, dan R\&D. Bandung: Alfabeta. 